\title{
REPRESENTAÇÃO DA FRONTEIRA BRASIL-PARAGUAI: ANÁLISE ENTRE OS PROFESSORES DE GEOGRAFIA DA ESCOLA ESTADUAL VESPASIANO MARTINS NO MUNICÍPIO DE AMAMBAÍ/MS
}

\author{
Sivaldo de Macedo Michenco ${ }^{1}$ \\ UFGD - Programa de Pós Graduação \\ Mestrado em Geografia \\ s.michenco@hotmail.com
}

RESUMO:

O presente trabalho está vinculado à dissertação, em andamento, do mestrado do Programa de Pós Graduação em Geografia da Universidade Federal da Grande Dourados e visa conceituar a relação entre a realidade de fronteira e a atuação do professor de geografia nessa realidade. O desenvolvimento do trabalho parte de uma pesquisa com professores de geografia da Escola Estadual Vespasiano Martins localizada no município de AmambaiMS. Nascem assim as seguintes perguntas: Quais as representações de fronteira de tais professores? Como os mesmos delineiam em suas praticas pedagógicas tais concepções? No município em questão está presente um conjunto de intermediações e diversidades de línguas (português [gaúchos, mato-grossenses], espanhol e guarani) e de práticas culturais mescladas que ratificam a análise proposta. O trabalho busca, assim, sua relevância na problemática mencionada, bem como no fato de que, nesta pesquisa sobre educação, o ponto de partida se constitui num duplo desafio: pensar a fronteira e o sujeito de fronteira a partir das concepções dos professores, mas também pensar a geografia como proposta de conhecimento do sujeito de fronteira.

Palavras-chave: Amambai, Fronteira, Ensino de Geografia

\section{REPRESENTATION OF THE BORDER PARAGUAY-BRAZIL: ANALYSIS AMONG SCHOOL GEOGRAPHY TEACHERS AT VESPASIANO MARTINS STATE SCHOOL IN AMAMBAÍ/MS}

\begin{abstract}
:
This work is linked to the dissertation, in progress, of the Master Geography Program of the Federal University of Grande Dourados and aims to conceptualize the relationship between reality and the role of border Geography teachers in this reality. The development of this work starts from a survey with Geography teachers at Vespasiano Martins State school in Amambai city - MS. The following questions arise: What are the representations of the border Brazil - Paraguay for these teachers? How do they outline in their pedagogical practices such conceptions? In this city is found a set of intermediaries and diversity of languages (Portuguese [gauchos, Mato- Grossenses], Spanish and Guarani) and cultural practices merged to ratify the proposed analysis. This essay searches its relevance in the problem mentioned and also the fact that this research on education is constituted by a double challenge: to think about the border and the border people from teachers conceptions, but also think of Geography as knowledge from the border people.

Keywords: Amambai, Frontier School of Geography
\end{abstract}




\section{INTRODUÇÃO}

O termo representação segundo Chartier (1988, p.17-18) "pode ser determinado pelo grupo que as forjam são percepções do social, discursos que produzem práticas e buscam legitimar ou justificar, para os próprios indivíduos as suas escolhas e condutas".

Esta análise nos faz refletir sobre o poder e a dominação presente nos discursos existentes nas lutas pelo monopólio da visão legítima do mundo social. As representações não são discursos neutros, produzem estratégias e práticas tendentes a impor uma autoridade, uma veneração, e mesmo a legitimar escolhas, não significam ilusões ou mentiras construídas sobre uma realidade social verdadeira e concreta. Elas são partes da realidade social, são produções simbólicas repletas de significado.

As lutas de representações têm tanta importância como às lutas econômicas para compreender os mecanismos pelos quais um grupo impõe, ou tenta impor, a sua concepção do mundo social, os valores que são os seus, e o seu domínio. (CHARTIER, 1988, p. 17)

Bourdieu (1989) ao discutir a idéia de região e de etnia coloca as representações mentais (língua, o dialecto ou o sotaque) e as representações objectuais (emblemas, bandeiras, insígnias, etc.) como práticas sociais capaz de desvelar aspectos importantes na sociologia (BOURDIEU, 1989, p. 112). Ainda para este autor "os princípios práticos do juízo quotidiano geralmente são substituídos pelos critérios logicamente controlados e empiricamente fundamentados da ciência" (BOURDIEU, 1989, p. 112). Tal fato, ao invés de orientar para a compreensão das funções práticas (cotidiano) da sociedade enquanto produtoras de efeitos sociais acabam por subordinar tais funções ao científico.

Só se pode compreender esta forma particular de luta das classificações que é a luta pela definição da identidade "regional" ou "étnica" com a condição de se passar para além da oposição que a ciência deve primeiro operar. (BOURDIEU, 1989, p.113)

Para o Geógrafo Norte Americano Edward Soja (1993) a partir da leitura das relações entre as práticas e representações do espaço em sua "reafirmação do espaço na teoria social crítica" (1993) "o espaço social é definido por relações sociais (políticas, econômicas, ideológicas), mas que, no entanto, também reage sobre estas".

Tal análise nos remete a pensar que o processo de formação de determinado espaço pode ser explicado a partir de níveis como as relações sociais, mas pode ser reestruturado também no plano das idéias e representações que são construídas sobre essas relações sociais. Assim, para Soja (1993) outra categoria pode ser definida, a categoria da representação do espaço.

Para Soja (1993, p.155) "a contingência espacial da ação social, entretanto, foi primordialmente reduzida à fetichização e à falsa consciência, e nunca recebeu de Marx uma interpretação materialista efetiva”. O que significa dizer que se por um lado às relações sociais como instâncias formadoras do espaço são amplamente aceitas no âmbito da teoria social, o mesmo não ocorre com o reconhecimento da contingência dessas mesmas relações a este mesmo espaço:

As teses sobre a contingência espacial das relações sociais, de que essas relações sociais de produção e de classe podem ser reconfiguradas e 
possivelmente transformadas, através da espacialidade evolutiva que as concretiza, ainda são, talvez, a parte da interpretação materialista do espaço mais difícil de ser aceita pelos estudiosos marxistas contemporâneos. (SOJA, 1993, p.155).

De fato, o suposto avanço na teoria do conhecimento a respeito da relação entre espaço e sociedade considerada aqui pelo reconhecimento de uma interação dialética entre eles, não é feito sem dificuldades, analisar a produção do espaço a partir das relações sociais incorre-se muitas vezes em analisar puramente aspectos econômicos, ou só aspectos culturais.

A apropriação da Teoria das Representações Sociais pela Geografia no Brasil foi posta, principalmente com a renovação experimentada pela Geografia Cultural ao longo dos anos 1980 e 1990. Nesse movimento de mudança ocorrido na Geografia os estudos e pesquisas sobre espaço, cultura e representações se multiplicaram no país. Roberto Lobato CORRÊA (1997), Zeny ROSENDAHL (1994), Salete KOZEL (2002), entre outros, encontram-se à frente desse movimento no Brasil.

Pensando nesse contexto é que buscamos a contribuição da geografia das representações para esse texto. Essa busca por representações da fronteira Brasil - Paraguai não visa separar, pôr a fronteira e seu sujeito em um pedestal ou redoma, muito menos falar de uma cultura pura; ao contrário, nossa análise parte do entendimento do professor sobre a sua realidade. É na narrativa desses professores, através da aplicação de questionários, que encontraremos subsídios para captar tais representações.

Chartier salienta ainda sobre o papel das narrativas e propõe uma nova forma de interrogar a realidade, tendo como base temas do domínio da cultura, buscando respostas sobre a relação alteridade-identidade. Para Chartier (1988, p. 18):

Os debates recentes entre os defensores da micro historia ou dos case studies e os da historia sociocultural seria herdeira direta da historia social, ilustram bem esta polarização constitutiva do campo das ciências sociais. Tentar ultrapassá-la exige, antes de mais, considerar os esquemas geradores das classificações e das percepções, próprios de cada grupo ou meio, como verdadeiras instituições sociais, incorporando sob a forma de categorias mentais e de representações coletivas as demarcações da própria organização social.

Tal análise nos remete a pensar sobre a construção do mundo social na fronteira a partir das percepções próprias de cada grupo (representações) e como tal a definição contraditória das identidades. Para quem vive como nós, "na fronteira" ser um ou ser outro é uma condição definitiva (nacionalidade) que permite mobilidade, uma vez que se o registro civil de cada um define a que lugar pertencemos, o "ir e vir" "de lá para cá e de cá para lá", nos limites internacionais, nos misturam e confundem ao mesmo tempo em que nos identificam. Alguns autores, a partir desses pressupostos denominaram as áreas fronteiriças como espaços de "cultura de fronteira".

Nessa vertente destaca-se o trabalho da antropóloga Laís M. Cardia que analisou entre 2006 e 2008 na fronteira Brasil (Assis Brasil-Acre), Peru (Iñapari-Madre de Dios) e Bolívia (Bolpebra-Pando) aspectos concatenados entre transformação do espaço, culturas de fronteira e diversidades culturais. Para a autora "os fenômenos presentes entre essas populações são resultantes de uma convivência cotidiana duradoura" (CARDIA, 2009, p. 108).

A fronteira como sistema acaba por gerar relações que necessitam precisamente desta linha política para subsistir. A tal ponto isto é assim 
que alguns autores falam de "cultura de fronteira" (Uriarte: 1994). Sem dúvida, é perigoso territorializar a cultura. Seria o mesmo que personalizar a fronteira. A fronteira não tem cultura, independentemente que de gere elementos compartilhados em uns e outros lugares fronteiriços. Neste sentido, seria mais apropriado falar de "culturas de fronteira" (Valcuende, 1998), de grupos que, a partir de suas próprias posições aprenderam a instrumentalizar, de forma diversa, esta demarcação político-administrativa. Um espaço polifônico, com dinâmicas culturais diferentes. (CARDIA, 2009, p. 112 - 113 apud URIART, 1994; VALCUENDE, 1998).

Esta análise aponta para o perigo em "territorializar à cultura" focalizando a singularização da cultura (cultura de fronteira) em detrimento da pluralidade cultural (culturas de fronteira). Em outros significados, torna-se complexo definir uma cultura de fronteira, haja vista que é importante refletir sobre as particularidades de cada linha fronteiriça.

Para Nogueira (2007, p. 33), autor que também analisa a fronteira numa vertente intercultural, "a existência ou não de interação entre as sociedades fronteiriças é resultado da história de relacionamento entre elas, da relação de dependência mútua, da porosidade para o movimento, e também das relações bilaterais entre os Estados".

Ricardo José Batista Nogueira analisou em sua tese de doutorado (NOGUEIRA, 2002), além de alguns desdobramentos publicados pela Revista Ateliê Geográfico (NOGUEIRA, 2007) o movimento mútuo das fronteiras Brasil (Tabatinga), Colômbia (Letícia). Para Nogueira (2007, p. 28) "a incorporação de uma leitura marxista privilegiou a instância econômica e a fronteira, por sua vez, aparece como um espaço a ser envolvido e transformado pela forma hegemônica de produção capitalista". Produção, reprodução, relação social, contradição, exploração, apropriação, valorização, alienação, dentre outros fazem parte do elenco discursivo dessa leitura marxista. (NOGUEIRA, 2007, p. 28).

Para pensar a fronteira como lugar de referência identitária, como um dado da cultura, tomando enfim, como base os pressupostos da geografia humanística, exige-se outro repertório conceitual, visto que a coerência metodológica não contempla o trânsito dos conceitos. Assim, teríamos como subsídio os seguintes conceitos: existir, identificar, significar, simbolizar, compreender, experienciar, perceber, habitar, ser, viver, etc. (NOGUEIRA, 2007, p. 28).

Esta análise é muito importante para a compreensão da categoria que o referido autor denomina de fronteira percebida. A fronteira também é vista como o lugar onde as diferenças se evidenciam e são geradoras de conflitos culturais e sociais. Por outro lado, é na fronteira que as distâncias também se estreitam e as diferenças passam por um processo de reelaboração.

Destarte, entendemos que na pesquisa em fronteira as abordagens socioeconômicas podem vir como elementos subsidiários na teorização social, assim como também as abordagens interculturais podem vir como elementos subsidiários, o que não podemos é modelar a pesquisa para o ortodoxismo marxista ou para o ceticismo multiculturalista.

Jacira Helena do Valle Pereira (2002) também se utilizando de uma abordagem intercultural focalizando os processos identitários fragmentados de migrantes de diferentes etnias na fronteira do Brasil (Ponta Porá) com o Paraguai (Pedro Juan Caballero) focandose nos intercâmbios fronteiriços e a indefinição desses processos identitários. Na primeira parte de sua tese, buscou anular estigma, quando apresentou as características da fronteira 
em questão, desmistificando-a, portanto desestigmatizando-a como um lugar de barbárie, um palco da contravenção e criminalidade, fruto, segundo ela da imagem construída pelo grande centro e muitas vezes ratificada por reportagens da mídia nacional.

Num contexto sócio cultural de fronteira, onde cotidianamente se entrecruzam diferentes etnias, em razão da intensa circulação de pessoas, a etnicidade desenvolve-se de forma inevitável. Na fronteira geográfica, a etnicidade é extremamente facilitada, ocorrendo uma articulação da fronteira dos grupos com a fronteira geográfica. (PEREIRA, 2003 P. 140)

Ao propor o desafio de buscar uma identidade regional para o sujeito fronteiriço, Jacira Helena questionou também a viabilidade de desvelar a identidade de um sujeito situado regionalmente, se vivemos num processo de globalização.

Questionamentos como esse traz a tona o sentido do uso da teoria multiculturalista. Embora o mundo globalizado se apresente como um mundo sem fronteira, percebe-se que as fronteiras que separam os sujeitos estão cada vez mais fortes, ainda que no imaginário. As discussões sobre gênero, etnia, identidade e unificação se fazem cada vez mais relevantes, pois os conflitos existem e a globalização acentuou o distanciamento humano. Não obstante aparentemente estejamos próximos de tudo e de todos por meio dos meios de comunicação este distanciamento tem se acentuado. A fronteira como nos lembra Bourdieu (1989) é produto de uma divisão arbitrária:

A fronteira nunca é mais do que o produto de uma divisão a que se atribuirá maior ou menor fundamento na "realidade" segundo os elementos que ela reúne, tenham entre si semelhanças mais ou menos numerosas e mais ou menos fortes [...] as "regiões" delimitadas em função dos diferentes critérios concebíveis (língua, habitat, amanho da terra, etc.) nunca coincidem perfeitamente. Mas não é tudo: a "realidade", neste caso, é social de parte a parte e as classificações mais naturais apóiam-se em características que nada têm de natural e que quer dizer, de um estado anterior da relação de forças no campo de lutas pela delimitação legitima. A fronteira, esse produto de um acto jurídico de delimitação, produz a diferença cultural do mesmo modo que é produto desta. (BOURDIEU, 1989, p. 114-115)

\section{O CONTEXTO DA PESQUISA}

Para primar pela clareza do texto faremos, em breves palavras, uma contextualização do município de Amambaí bem como da Escola Estadual Vespasiano Martins pertencente a este município. 


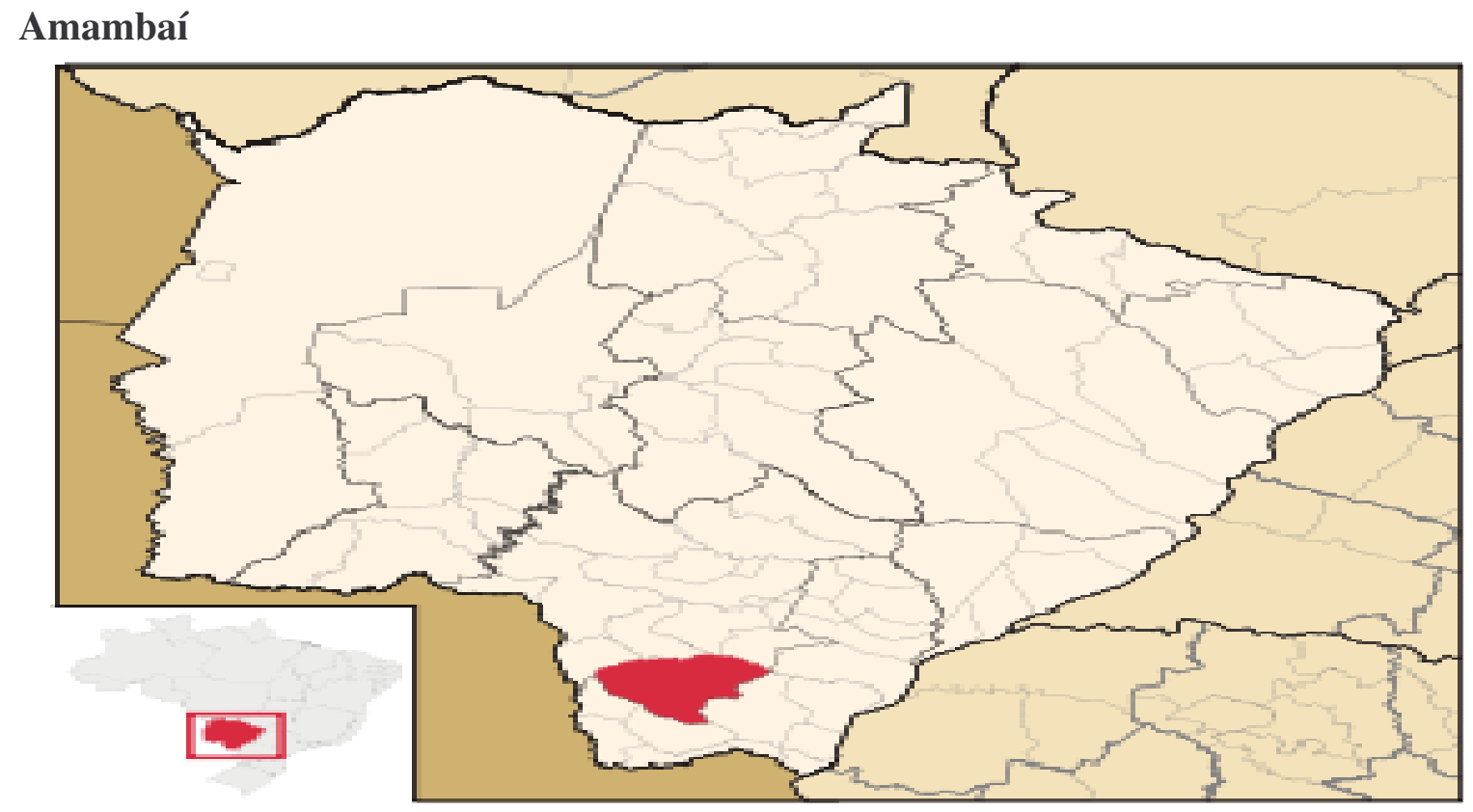

Fonte: http://pt.wikipedia.org/wiki/Amambai

Município localizado na faixa de fronteira (caracterizada pelo limite de $150 \mathrm{Km}$ de largura que define o limite entre diversas diferentes países e o Brasil, estabelecida pela Lei $n^{\circ}$ 6.634/79 e regulamentada pelo Decreto $n^{\circ}$ 85.064, de 26 de agosto de 1980) está a 364 $\mathrm{km}$ de Campo Grande (capital do Estado de Mato Grosso do Sul). De acordo com o censo de 2006, atualmente possui aproximadamente 34.500 habitantes. Limita-se ao Norte com os municípios de Aral Moreira e Ponta Porã; ao Sul com Tacuru e Iguatemi; a Leste Juty e Caarapó e a Oeste, com o Município de Coronel Sapucaia. De acordo com Oliveira (2005 p. 396), Amambai está localizada fora da linha, porém na faixa de fronteira, a $60 \mathrm{~km}$ da mesma e observa-se nessa cidade "uma situação especial com potencial".

[...] "Há vários fatos que nos possibilitam constatar que a situação encontrada neste tipo tem significado potencial. Enfatizamos dois de maior relevância: Há um arranjo espacial do lado paraguaio com a profissionalização da agropecuária em, praticamente, toda a região de fronteira. Por outro lado, no Brasil também está acontecendo um rearranjo espacial, com redefinições no conjunto produtivo, a partir do volume de assentamentos de trabalhadores rurais, alocados na faixa de fronteira". (Oliveira, 2005, P. 396)

De acordo com o grupo RETIS [...] "Os negócios ligados às atividades ilegais estimulam da pior maneira possível a economia urbana das localidades fronteiriças, uma vez que atraem indivíduos de todas as regiões do país sem comprometimento nenhum com o lugar. Curiosamente, no caso das Sub-regiões do Cone Sul-mato-grossense e Dourados, municípios não-lindeiros como Dourados e Amambaí, não "contaminados" pela imagem negativa dos municípios lindeiros, são os mais importantes núcleos logísticos do tráfico e do contrabando, e talvez os que mais capitalizaram de forma produtiva seus ganhos." (BRASIL, 2005 p. 59).

Tal afirmação nos remete a pensar sobre uma inversão de valores do núcleo logístico do narcotráfico, a inserção de uma política ferrenha de combate ao tráfico pelo governo federal nos últimos dez anos e os investimentos maciços do capital agrícola, como 
é o caso das cooperativas já citadas, trouxeram uma conjuntura econômica diferenciada para Amambaí, onde é visível que não existe mais uma interdependência da capitalização do narcotráfico, não rara às vezes vemos ainda cenas de apreensão de drogas, principalmente de jovens que se aventuram em busca de melhores condições de vida a partir dessa atividade ilícita, mas o que se vê agora é um aumento no número de usuários, o que justifica a afirmação de tal inversão de valores.

\section{Escola Estadual Vespasiano Martins}

A Escola Estadual Vespasiano Martins foi criada no dia 21 (vinte e um) de fevereiro de 1986. É uma das seis Escolas Estaduais do município de Amambai-MS. Está localizado à Rua Francisco Serejo Neto nº 1050 na Vila Alba e atende a comunidade periférica da cidade de Amambaí. A Unidade Escolar conta hoje com 1.216 (um mil duzentos e dezesseis) alunos freqüentando de forma ativa à escola e cerca de 1400 (um mil quatrocentos) alunos conforme consta nos registros da matricula inicial.

Ao analisar algumas características do ensino de geografia na referida escola percebe que nas relações de ensino/aprendizagem não há práticas pedagógicas análogas à região fronteiriça e voltada para os anseios dessas populações. Quando há uma prática pedagógica mais crítica, também não percebemos tais indagações, argumentações e/ou analogias. No entanto, é preciso reconhecer que existem certas práticas pedagógicas mais crítica e tal fato deve-se a uma admissão de uma série de profissionais, visto que foram oferecidos concursos públicos no ano de 1999 e 2005. Além disso, o aumento de vagas no ensino superior, bem como a interiorização desse ensino, principalmente com a Universidade Estadual de Mato Grosso do Sul - UEMS com 15 unidades no Estado acabou contribuindo de maneira incisiva nesse processo.

Ao historiar as práticas pedagógicas dos profissionais da área da geografia, ou áreas afins, que lecionaram na escola na década de 1990 percebemos que os mesmos guiavam-se ortodoxamente pelo manual didático e a escassez de recursos tecnológicos sofisticados comprometia ainda mais o seu trabalho. Alves (1998) define essa realidade como uma verdadeira "camisa de força".

[...] "Outra incongruência dessa forma de organização do trabalho didático se manifesta, ainda na renitência com que professores se mantêm aferrados aos recursos do passado. Como a própria formação dos educadores se deu segundo os condicionamentos do quadro exposto, também eles realizam, rotineiramente, uma prática que o reforça e o reproduz. Contudo, já não há como deixar de empreender uma rigorosa crítica ao trabalho didático e, principalmente, de estabelecê-lo sobre novas bases. Essas bases não são outras que não as constituídas pelos recursos tecnológicos de nossa época." (ALVES, 1998, P. 57).

Ainda hoje é possível perceber, no cotidiano, no bojo e no cerne das discussões, discursos falaciosos, alienantes e na maioria das vezes equivocados dos educadores. É visto que há uma necessidade de que o professor tenha uma formação que se converta em instrumento de qualificação contínua, ampliando sua capacidade de reflexão sobre o processo ensino/aprendizagem. A concepção norteadora desses indivíduos deve ser trabalhada dentro de um processo de superação de antigas formulações teóricas, para isso é preciso "democratizar" os diferentes níveis de ensino, mestrado e doutorado, por exemplo.

Para o Professor de geografia Danilo Ferreira Sebastião, que leciona no período matutino e no período noturno é o responsável pela sala de tecnologia, quando um 
professor se torna um facilitador do processo de ensino-aprendizagem junto à sala de tecnologia, os alunos passam a tratá-lo de forma diferente, com maior admiração.

[...] "Isso acontece, pelo simples fato de que eles percebem que o professor sabe se comunicar e utilizar o instrumento que eles tanto gostam. Evidentemente, essa relação trará maior valorização para o professor, fará com que este procure mais ainda, mecanismos para seu crescimento profissional e pessoal".

Ao analisar também a formação dos profissionais que lecionaram no período da década de 1990 percebemos que havia uma escassez de profissionais habilitados. Ver tabela abaixo:

Década de 1990

\begin{tabular}{|l|l|}
\hline PROFISSIONAIS & HABILITAÇÃO \\
\hline Antônia Oceny P. da Silva & Pedagogia \\
\hline Cleonice de Paula & Letras \\
\hline Dirlei Rosangela Guerini & Letras \\
\hline Débora Gonçalves Coradini & Pedagogia \\
\hline Dorací Tobias & Letras \\
\hline Elenir Marcanth de Freitas & Magistério \\
\hline Ércia Tobias Quaresma & Geografia \\
\hline Izabel Cristina de Paula Pinto & Magistério \\
\hline João Vicente Ferreira & Letras \\
\hline José Doe Silva & Teologia \\
\hline Lucia Helena Rodrigues Calagno & $*$ \\
\hline Maria Izabel Ferreira Diniz & Geografia \\
\hline Mirian Santana da Rocha & Pedagogia \\
\hline Richard Alexandre Coradini & Matemática \\
\hline Renata Maria Castanhari & Geografia \\
\hline Sheila Aparecida Sarmento Lopes & Letras \\
\hline Zaira Maria Vasconcelos & Geografia \\
\hline Zenilda de Souza Martins & Pedagogia \\
\hline
\end{tabular}

Fonte: Registros e diários de classe da Secretaria da Escola Estadual Vespasiano Martins. Junho de 2009 (org) Michenco 2009

* Não foram encontradas documentações nos arquivos

Década de 2000

\begin{tabular}{|l|l|}
\hline PROFISSIONAIS & HABILITAÇÃO \\
\hline Adélzio da Silva & Geografia \\
\hline Danilo Ferreira Sebastião & Geografia \\
\hline Jùlio Cezar Miranda & Geografia \\
\hline Lorivaldo Farinea & Geografia \\
\hline Luciana Nogueira & Geografia \\
\hline Maria Izabel Ferreira Diniz, & Geografia \\
\hline Rosimere Ferraz Fernandez & Geografia \\
\hline Sivaldo de Macedo Michenco & Geografia \\
\hline Zaira Maria Vasconcelos & Geografia \\
\hline Zenilda de Souza Martins & Pedagogia \\
\hline
\end{tabular}


Fonte: Registros e diários de classe da Secretaria da Escola Estadual Vespasiano Martins. Junho de 2009 (org) Michenco 2009

Mas vejamos também que este não era um problema só da geografia, mas de todas as outras disciplinas. Em entrevista com a coordenadora da Escola, Erli Fernandes, a mesma relata:

[...] "Fiz o antigo magistério, lecionava matemática de $5^{a}$ a $8^{a}$ série nessa escola no início da década de 1990, estudava apenas os conteúdos e repassava-os para os alunos, vejo que eu apenas fragmentava as partes da ciência, hoje os professores cada um em sua área conseguem fazer uma interpretação e contextualização do todo, conseguem trazer situações problemas para os alunos".

Outro avanço também está ligado ao próprio desenvolvimento econômico da região, onde a mesma se tornou supostamente promissora tanto pela expansão da fronteira agrícola, como por um "controle" no que diz respeito ao narcotráfico, liberando assim os professores e jovens para práticas mais concretas nas realizações de projetos. A comunidade passa ter também maior participação na escola.

Mesmo com tais avanços é visível, no cotidiano escolar, que as práticas pedagógicas desses profissionais vêm sendo gradativamente conduzidas para a reprodução social, principalmente quando se fala em "aprender para o vestibular". O confronto entre a busca pelo sentido de "estar ali" com o cumprimento das normas da política educacional do Estado (Gestão 2007 - 2010) nos remete a pensar claramente na teoria "criticoreprodutivistas". Para Saviani (1997, p. 17).

Tomando como critério de criticidade a percepção dos condicionantes objetivos, denominarei as teorias do primeiro grupo de "teorias não críticas" já que encaram a educação como autônoma e buscam compreendê-la a partir dela mesma. Inversamente, aquelas do segundo grupo são críticas uma vez que se empenham em compreender a educação remetendo-a sempre a seus condicionantes objetivos, isto é, aos determinantes sociais, vale dizer à estrutura socioeconômica que condiciona a forma de manifestação do fenômeno educativo. Como, porém, entendem que a função básica da educação é a reprodução da sociedade, serão por mim denominadas de "teorias criticoreprodutivistas".

Na política educacional do Estado (Gestão 2007 - 2010) percebe-se claramente que não há uma preocupação com investimentos, mas sim com a organização do interior das escolas. Partindo da premissa de que é necessário, a partir da estrutura já encontrada, reformular o aspecto da gestão escolar, volta-se para a organização do planejamento pedagógico e para a aplicação do projeto político pedagógico da escola.

Um exemplo dessa política é a formação continuada intitulada "Programa conhecimento em foco" com diretores, Coordenadores e professores. No referido curso orienta-se os professores a seguir um referencial de conteúdos do Estado, onde semanalmente ou quinzenalmente os professores terão que apresentar à coordenação da escola seu planejamento com habilidades e competências de cada conteúdo, que será averiguado pela assessoria técnica do governo. Cabe então ao professor cumprir com o conteúdo especificado. Não seria melhor cada escola ter acesso a muitas propostas e 
conteúdos curriculares, para partir da sua própria realidade e experiência construírem o projeto de escola que deseja?

Os próprios PCNs trazem "em si" a autonomia para a construção de projetos pedagógicos que visem às diferenciações regionais, locais e/ou culturais, colocando a geografia como disciplina fundamental nessa autonomia. Para os Parâmetros Curriculares Nacionais (PCNs):

O aluno do século XXI terá na ciência geográfica importante fonte para sua formação como cidadão que trabalha com novas idéias e interpretações em escalas onde o local e o global definem se numa verdadeira rede que comunica pessoas, funções, palavras, idéias. "Assim compreendida, a Geografia pode transformar possibilidades em potencialidades (re) construindo o cidadão brasileiro" e fornecendo ao aluno a educação científica e tecnológica necessária ao seu desenvolvimento (BRASIL, 1999, p.312).

Analisando o Projeto Político Pedagógico dessa escola não encontramos propostas de projetos que venham a atender às especificidades desses alunos, principalmente por estarem em área de fronteira. $\mathrm{O}$ que existe é apenas uma diferenciação curricular quando diz respeito à questão da língua estrangeira, pois na maioria dos municípios brasileiros optou-se pelo idioma inglês e no município de Amambai optou-se pelo idioma espanhol.

Mas será que apenas essa diferenciação em termos de proposta curricular é suficiente para essa realidade? E os professores como trabalham a fronteira? Haja vista estarem em área de fronteira.

$\mathrm{Na}$ persecução de encontrar respostas para tais indagações passaremos à parte empírica deste trabalho.

\section{Professores de Geografia da Escola Estadual Vespasiano Martins: Representação da Fronteira Brasil - Paraguai}

Analisando quais as representações desses professores sobre a fronteira Brasil Paraguai, consequentemente estaremos avaliando tais concepções no cotidiano escolar, haja vista que tais representações se refletem nesse cotidiano.

Para tanto foram aplicados questionários para os professores Danilo Ferreira Sebastião, Julio Cezar Miranda e Luciana Nogueira, professores titulares da disciplina de geografia nos três turnos de funcionamento dessa escola. Os dois primeiros formados em Geografia pela Universidade Estadual do Paraná - Campus de Campo Mourão-PR e a terceira formada pela Universidade para o desenvolvimento da região do Pantanal UNIDERP - Unidade de Campo Grande-MS.

Os questionários aplicados a estes professores continham as seguintes perguntas:

1) Qual a sua concepção de fronteira? ;

(2) É possível perceber uma singularidade/identidade de fronteira em Amambaí? E na Escola, na lida com os alunos? Se existe tal singularidade/identidade quais os reflexos dessas em sala de aula?;

3) O conceito de fronteira vem sendo muito discutido dentro da Ciência Geográfica. Quais autores você poderia mencionar sobre a discussão desse conceito geográfico? ;

4) Quais as representações simbólicas (discursos regionalistas) que você percebe em sala de aula que tenha relação com a realidade de fronteira, ou que constrói o ser fronteiriço? Ou isso não acontece? 
Diante das variedades dos elementos representados dentro dos questionários analisados formulamos grupos a partir de elementos predominantes onde não pretendemos aqui elucidar classificações para as fronteiras, mas sim facilitar a compreensão dessas representações de fronteira dos professores a partir de algumas categorias convergentes com as análises dos questionários.

Assim tais categorias ficaram definidas como:

- Noção de fronteira que expressa o Módus vivendi a partir da idéia da fronteira como lugar, do encontro entre culturas;

- Noção de fronteira como locais geradores de conflitos a partir de desencontros, de diferenças culturais, etc.;

- Noção de fronteira como linha demarcatória entre Países, Estados ou Municípios;

- Noção de fronteira que expressa o Módus Vivendi a partir da idéia da contravenção.

$\mathrm{Na}$ primeira questão apresentada aos professores: "Qual a sua concepção de fronteira?" tivemos como intuito perceber a concepção de fronteira e não da fronteira Brasil - Paraguai, nesse sentido obtivemos as seguintes respostas:

"Limite territorial, sócio cultural de algo; seca ou abstrata, tido como divisão do espaço geográfico (...)”. (DFS)

"Divisão de cultura, etnia no aspecto humano e divisão, limite territorial, quando se trata de cidades, Estados, e países (...)". (JCM)

"Geograficamente, seria a região limite entre dois ou mais países, com características próprias, tais como: trocas culturais, atuação militar, relações econômicas próprias, atuação do "poder paralelo", etc. (...)". $(\mathrm{LN})$

Percebe-se que tais professores têm sua conceituação sobre fronteira, mas predomina a representação de fronteira como linha demarcatória com algumas oscilações para a questão étnica, mas ainda fundada na concepção tradicional.

$\mathrm{Na}$ segunda questão apresentada aos professores: "É possível perceber uma singularidade/identidade de fronteira em Amambaí? E na Escola, na lida com os alunos? Se existem tal singularidade/identidade quais os reflexos dessas em sala de aula?", obtivemos as seguintes respostas:

"Sim. Na escola, sala de aula se reflete ainda mais essa singularidade porque se observa certo comportamento diferente das demais cidades do Estado que estão distantes dessa fronteira territorial (...)”. (DFS).

"Dificuldades de comunicação com descendentes paraguaios e etnia caiuá, assim como resistência a regras e normas estabelecidas (...)”. (JCM)

"Certamente, fica evidente quando observado aspectos culturais vindos da cultura indígena e paraguaia, principalmente na música, culinária, língua, etc. Devido às facilidades encontradas pelo narcotráfico, fica clara sua influência em nossa cidade. Com certeza na escola é fácil identificar a 
identidade de fronteira, ao analisar os pontos já levantados anteriormente. $\mathrm{Na}$ grande maioria das vezes os reflexos de tal identidade são desconsiderados, ficando assim restrito a discursos de alguns professores em determinados conteúdos ou momentos, percebe-se uma valorização até mesmo maior de culturas externas (...)” (LN).

Ao analisarmos tais transcrições observamos que para esses professores existe uma singularidade/identidade de fronteira em Amambaí, haja vista que colocam a fronteira como espaço de convivência, com o outro e de contradições compartilhadas, como por exemplo: O fato de estarem em área de fronteira se diferencia das demais cidades do Estado ( $1^{\circ}$ comentário); Dificuldade de comunicação e resistência a regras e normas por descendentes de paraguaios e etnia caiuá ( $2^{\circ}$ comentário); influencia cultural através da música, culinária, língua, do narcotráfico ( $3^{\circ}$ comentário). Para Nogueira $(2007$, p. 32) [...] "o dado particular fundamental da fronteira é justamente o fato da convivência, regra geral aproximada, com o outro, com a diferença nacional, que remete aos símbolos próprios a cada nação, a história, a cultura, ao nacionalismo".

Concordamos com o autor e entendemos que essa convivência permite nos pensar como a fronteira influencia nosso viver e nosso ser como aluno, como professor de geografia e como cidadãos.

$\mathrm{Na}$ terceira questão apresentada aos professores: "O conceito de fronteira vem sendo muito discutido dentro da Ciência Geográfica. Quais autores você poderia mencionar sobre a discussão desse conceito geográfico?" obtivemos as seguintes respostas:

"Yves Lacoste, Milton Santos, Maria Lúcia Salgado e Pierre Bourdieu (...)". (DFS)

"Melhem Adas e Milton Santos (...)”. (JCM)

"ñ conheço muitos, li um artigo do Cláudio Benito Ferraz, publicado no Sciélo (...)". (LN)

Tais considerações nos remetem a pensar também sobre a relação da geografia escolar com o mundo acadêmico, intrínsecos e muitas vezes divergentes nessa relação, pois quando propomos aos professores para mencionar autores que discutem fronteiras percebemos certa preocupação destes, haja vista que se sentem distantes das discussões teóricas da universidade. Nessa linha de análise Kaercher (2003 p. 183) enfoca que:

Nossos intelectuais desligaram-se de nossa realidade. Não criaram um pensamento próprio sintonizando com nossas raízes e nossa população. Deixaram de ser criadores e passaram a ser conhecedores de teorias que muito pouco nos ajudaram a sair desse subdesenvolvimento econômico e intelectual.

Concordamos com o autor e analisamos que tal distanciamento provoca um retardo no desenvolvimento da educação. No entanto ultrapassar as rígidas fronteiras entre a universidade e a educação básica torna-se um desafio que implica repensar o papel da universidade e das licenciaturas, buscando um novo pensar, novas relações e novas conjunturas educacionais.

É preciso entender também que tanto a geografia escolar quanto a universidade advém de uma práxis educacional única e que ambos são frutos da formação históricoeducacional de nosso país. Sobre esse assunto Melo (1979) busca pensar que tal problema está na própria formação universitária enfatizando a ineficiência do nível médio de ensino 
como origem do problema e que essa ineficiência se transforma em um circulo vicioso de formação que culminará com um distanciamento entre teoria e prática, mundo acadêmico e ensino médio. Para este autor:

São bem conhecidos os vícios e distorções do ensino universitário brasileiro. Sua análise aqui, quando não fosse ociosa, seria pelo menos inoportuna. Mas ao nosso objetivo interessa lembrar que, para esses vícios e distorções, contribui substancialmente o muito baixo grau de eficiência do ensino médio. (MELO 1979, P. 70)

Para Oliva (2005, p. 34) [...] "A renovação da geografia é muito complexa e desigual no âmbito acadêmico e as relações entre essas esferas e o universo do ensino médio são marcadas por inúmeras dificuldades". No entanto, mesmo conhecendo os vícios e as distorções do ensino universitário e as inúmeras dificuldades na relação entre esses mundos é preciso entender que a apropriação da força e o vigor da geografia renovada são de fundamental importância para se pensar novas conjunturas educacionais. Conjunturas essas que devem ser voltadas para a realidade do aluno, partindo do que se estuda na escola em direção a vida cotidiana, de um ensino sistematizado e correlacionado com a vida fora da escola, onde o conhecimento científico elaborado seja transformado em conteúdo pedagógico e, portanto, em recurso didático necessário à prática social desenvolvida no interior da escola.

Nessa mesma linha de pensamento Castrogiovanni (2000 p. 11) relata que [...] "existe ainda pouca aproximação da escola com a vida, com o cotidiano dos alunos. A escola não se manifesta atraente frente ao mundo contemporâneo, pois não dá conta de explicar e textualizar as novas leituras de vida". Concordamos com o autor e a partir dessas reflexões pensamos que é fundamental que o professor de geografia, que está na ativa, esteja sempre em contato com o meio acadêmico participando do debate teórico/metodológico que vem sendo travado na universidade.

Este debate tem trazido à tona um conjunto de questões que levam aqueles que produzem o saber geográfico a se indagarem a respeito dessa produção. Tem permitido também aos professores se posicionarem acerca das implicações ideológicas embutidas em sua disciplina. (OLIVEIRA, 1989, p. 141)

Dessa maneira entendemos que é através de sua inserção nesse debate que fará a sua opção consciente do caminho crítico que a geografia e a escola devem ter, confrontando os dois tipos de conhecimento, o do cotidiano (as representações sociais) e o científico, considerando estes como parâmetros iniciais para a mobilização do educando rumo a um processo de emancipação.

É neste contexto que destacamos a importância dessa interatividade, até mesmo porque tal interatividade permitirá aos professores retomar as discussões teóricas sobre os conceitos da geografia que lhe são próprios, principalmente o conceito de fronteira.

E na quarta e última questão apresentada aos professores, "Quais as representações simbólicas (discursos regionalistas) que você percebe em sala de aula que tenha relação com a realidade de fronteira, ou que constrói o ser fronteiriço? Ou isso não acontece?", obtivemos as seguintes respostas:

"A utilização de termos característicos como: "Pé de Chipa", "Borracho", "La prata", etc. Não raramente observa-se o termo "Bugre" utilizado de maneira preconceituosa (...)". (DFS) 


\begin{abstract}
"Ocorre na linguagem, nos hábitos e cotidiano; palavras como inticar (provocar), alimentação (mandioca, Bori - Bori)" (...) (JCM).

"No diálogo entre os alunos, palavras são acrescidas como "Porã", palavra guarani que significa "bonito" ou "bom", devido ao convívio com os indígenas e paraguaios (...)" (LN).
\end{abstract}

Percebe-se nessas respostas que os professores são observadores das representações sociais do cotidiano. Tais observações podem contribuir, por exemplo, com o conteúdo sobre etnias, desmistificando o imaginário popular sobre o indígena e o paraguaio migrante, ditos "preguiçosos e tomadores de tererê" e suas relações com o sulista dito "empreendedor da agricultura".

\title{
CONSIDERAÇÕES FINAIS
}

Nessa perspectiva, consideramos que o presente texto proporciona uma reflexão sobre o conceito de fronteira através dos subsídios teóricos e a partir da ótica dos professores envolvidos com suas práticas de ensino. A ação pedagógica destes professores é muito importante e de certa maneira interventiva, para contribuir e favorecer no processo de ensino e aprendizagem, não só da Geografia como de todas as disciplinas.

Há necessidade de integrar e interligar tais representações de fronteira com reflexões mais contextualizadas, considerando o conhecimento prévio dos alunos, relacionando-os ao conhecimento científico no sentido de superar o senso comum, passando de uma linguagem do cotidiano para uma linguagem geográfica para que de fato haja uma aprendizagem significativa.

Ressaltamos ainda sobre a importância de trabalhar com os alunos conteúdos que fundamentem o papel histórico que têm desempenhado, por exemplo, as formas de poder exercidas por determinadas classes sociais na construção da sociedade de tal realidade fronteiriça, e assim por diante, buscando-se alcançar o sentido no âmbito interpessoal, que contém algo de subjetivo.

\section{FONTES}

ESCOLA ESTAdUAl VeSPASIANO MARTINS. Projeto Político Pedagógico - PPP. Reformulado em 2006.

ESCOLA ESTADUAL VESPASIANO MARTINS. Professores de Geografia na Escola Estadual Vespasiano Martins nas décadas de 1990 e 2000. Registros e diários de classe da Secretaria da Escola Estadual Vespasiano Martins. Junho de 2009.

FERNANDES, Erli. O ensino de geografia na Escola Estadual Vespasiano Martins. 2010. Entrevista.

SEBASTIÃO, Danilo Ferreira. O ensino de geografia na Escola Estadual Vespasiano Martins. 2010. Entrevista.

WIKIPEDIA. Estado do Mato Grosso do Sul: Mapa político do Mato Grosso do Sul. Disponível em http://pt.wikipedia.org/wiki/Amambai. Acesso em 21 Set. 2010, 15h35min $\min$. 


\section{BIBLIOGRAFIA}

ALVES, Gilberto Luiz. A produção da escola pública contemporânea. Campinas: Faculdade de Educação/UNICAMP, 1998.

BOURDIEU, Pierre. O poder simbólico. Trad. Fernado de Tomaz. Lisboa: Difel. 1989.

BRASIL. Ministério da Integração Nacional. Secretaria de Programas Regionais. Programa de Desenvolvimento da Faixa de Fronteira. Proposta de Reestruturação do Programa de Desenvolvimento da Faixa de Fronteira/Ministério da Integração Nacional, Secretaria de Programas Regionais, Programa de Desenvolvimento da Faixa de Fronteira, Brasília: Ministério da Integração Nacional, 2005.

BRASIL. MEC. SEMTEC. Parâmetros Curriculares Nacionais para o Ensino

Médio. Brasília: Secretaria de Educação Média e Tecnologia, 1999.

CARDIA, Laís M. Espaço e culturas de fronteira na Amazônia ocidental. In: Revista Ateliê Geográfico v. 3, nº. 7. Universidade Federal de Goiás, Goiás, 2009.

CASTROGIOVANNI, Antônio Carlos. (Org.). Estudar o lugar para compreender o mundo. In: Ensino de Geografia: práticas e textualizações no cotidiano. Porto Alegre: Mediação, 2000.

CHARTIER, Roger. A história cultural: entre práticas e representações. Lisboa: Difel, 1988.

CORRÊA, R. L., Trajetórias geográficas, Rio de Janeiro, Bertrand Brasil, 1997.

KAERCHER, Nestor André. Desafios e utopias no ensino de geografia. In: CASTROGIOVANNI, A. C; CALlAI, H. C; SCHAFFER, N. O; KAERCHER, N. A. (Orgs.). Geografia em sala de aula práticas e reflexões. Porto Alegre: Editora da UFRGS, $4^{\text {a }}$ Ed. 2003.

KOZEL, S. As representações no geográfico In: MENDONÇA, F; KOZEL, S. Elementos de Epistemologia da Geografia Contemporânea. Curitiba: Editora da UFPR, 2002.

MELO, Mario Lacerda de. A Universidade e a formação do geógrafo agrário no Brasil. Boletim de geografia teorética V. 9 Nº 17 e 18. Rio Claro-SP: AGETEO, 1979.

NOGUEIRA, Ricardo José Batista. A divisão da monstruosidade geográfica. Tese de doutorado, USP, São Paulo, 2002.

Fronteira: Espaço de referência identitária? In: Revista Ateliê Geográfico v. 1, nº. 2. Universidade Federal de Goiás, Goiás, 2007. 
OLIVA, Jaime Tadeu. Ensino de Geografia: um retrato desnecessário. In: CARLOS, Ana Fani Alessandri (Org.). A Geografia na sala de aula. $7^{\mathrm{a}}$ ed. São Paulo: contexto, 2005.

OLIVEIRA, Ariovaldo Umbelino de (org.). Para onde vai o ensino de geografia? São Paulo: Contexto, 1989.

OLIVEIRA, Tito Carlos Machado de. Território sem limites. Editora UFMS, Campo Grande, 2005.

PEREIRA, Jacira Helena do Valle. Educação e Fronteira: processos identitários de migrantes de diferentes etnias. São Paulo: USP, (Tese de Doutorado), 2002.

- Processos identitários da segunda geração de migrantes de diferentes etnias na fronteira Brasil-Paraguai. In: MARIN, Jérri R; VASCONCELOS, Cláudio A de (Orgs.) História Região e identidades. Campo Grande: Editora da UFMS, 2003.

ROSENDAHL, Zeny. Porto das Caixas: espaço sagrado da Baixada Fluminense. Tese de Doutorado (Departamento de Geografia da USP). São Paulo, 1994.

SAVIANI, Dermeval. Escola e democracia. Autores Associados. Campinas, 1997

SOJA, Edward. Geografias Pós-Modernas: A reafirmação do espaço na teoria social crítica. Rio de Janeiro, Tradução [da 2a ed. Inglesa], Editora Jorge Zahar, 1993.

Notas

\footnotetext{
${ }^{1}$ Professor da rede pública do Estado do Mato Grosso do Sul - Graduado em Geografia pela Universidade Estadual do Paraná - UEPR - Campus de Campo Mourão e Mestrando do Programa de Pós Graduação em Geografia da Universidade Federal da Grande Dourados-UFGD
} 